\title{
Identification of novel QTL contributing to barley yellow mosaic resistance in wild barley (Hordeum vulgare spp. spontaneum)
}

\author{
Yuhan Pan ${ }^{1 \dagger}$, Juan Zhu ${ }^{1 \dagger}$, Yi Hong ${ }^{1}$, Mengna Zhang ${ }^{1}$, Chao Lv ${ }^{1}$, Baojian Guo ${ }^{1}$, Huiquan Shen ${ }^{2}$, Xiao Xu ${ }^{2}$ and
} Rugen $\mathrm{Xu}^{1 *}$

\begin{abstract}
Background: Barley yellow mosaic disease (BYMD) caused by Barley yellow mosaic virus (BaYMV) and Barley mild mosaic virus (BaMMV) seriously threatens the production of winter barley. Cultivating and promoting varieties that carry disease-resistant genes is one of the most powerful ways to minimize the disease's effect on yield. However, as the BYMD virus mutates rapidly, resistance conferred by the two cloned $R$ genes to the virus had been overcome by new virus strains. There is an urgent need for novel resistance genes in barley that convey sustainable resistance to newly emerging virus strains causing BYMD.
\end{abstract}

Results: A doubled haploid (DH) population derived from a cross of SRY01 (BYMD resistant wild barley) and Gairdner (BYMD susceptible barley cultivar) was used to explore for QTL of resistance to BYMD in barley. A total of six quantitative trait loci ( $q R Y M-1 H, q R Y M-2 H a, q R Y M-2 H b, q R Y M-3 H, q R Y M-5 H$, and $q R Y M-7 H)$ related to BYMD resistance were detected, which were located on chromosomes $1 \mathrm{H}, 2 \mathrm{H}, 3 \mathrm{H}, 5 \mathrm{H}$, and $7 \mathrm{H}$. Both $q R Y M-1 \mathrm{H}$ and $q R Y M-2 \mathrm{Ha}$ were detected in all environments. $q R Y M-1 H$ was found to be overlapped with rym7, a known $R$ gene to the disease, whereas $q R Y M$ $2 \mathrm{Ha}$ is a novel QTL on chromosome $2 \mathrm{H}$ originated from SRY01, explaining phenotypic variation from 9.8 to $17.8 \%$. The closely linked InDel markers for qRYM-2Ha were developed which could be used for marker-assisted selection in barley breeding. $9 R Y M-2 H b$ and $9 R Y M-3 H$ were stable QTL for specific resistance to Yancheng and Yangzhou virus strains, respectively. qRYM-5H and qRYM-7H identified in Yangzhou were originated from Gairdner.

Conclusions: Our work is focusing on a virus disease (barley yellow mosaic) of barley. It is the first report on BYMDresistant QTL from wild barley accessions. One novel major QTL ( $q R Y M-2 H a)$ for the resistance was detected. The consistently detected new genes will potentially serve as novel sources for achieving pre-breeding barley materials with resistance to BYMD.

Keywords: Wild barley (Hordeum vulgare spp. spontaneum), Barley yellow mosaic disease (BYMD), Quantitative trait loci (QTL), InDel markers

\footnotetext{
*Correspondence: rgxu@yzu.edu.cn

${ }^{\dagger}$ Yuhan Pan and Juan Zhu contributed equally to this work.

${ }^{1}$ Key Laboratory of Plant Functional Genomics of the Ministry of Education / Jiangsu Key Laboratory of Crop Genomics and Molecular Breeding / Jiangsu Co-Innovation Center for Modern Production Technology of Grain Crops / Institutes of Agricultural Science and Technology Development, Yangzhou University, Yangzhou 225009, Jiangsu, China

Full list of author information is available at the end of the article
}

\section{Backgrounds}

Barley (Hordeum vulgare spp. vulgare) is probably the earliest domesticated crop, which played an important role in the history of world agriculture [1]. Nowadays, barley is the fourth largest cereal crop in the world after maize, rice, and wheat [2]. For the last few decades, the soil-borne BYMD once seriously affected the yield of winter barley in the world [3-5]. In Europe, the prevalence 
of the disease result in up to $50 \%$ yield loss during each growing season [6, 7]. In China, a complete yield loss in barley has been recorded in the mid-1970s $[8,9]$.

BYMD belongs to soil-borne filamentous viruses transmitted by the vector Polymyxa graminis, caused by BaYMV and BaMMV $[10,11]$. Before winter, the fungal vector invades the roots of barley seedlings and releases the virus before being transported from the roots to the leaves following water movement $[12,13]$. Along with temperature rises in the next spring, the virus rapidly proliferates in the leaves of the susceptible varieties, bleaching chloroplasts and ultimately developed small, kite-shaped patches either pale green or yellow in appearance. Subsequently, the patches shape into chlorotic streaks, causing the death of older leaves, plant drawing, and panicle number reductions, ultimately decrease the grain yield [8]. The two viruses that cause BYMD are the positive-sense single-stranded RNA virus ('+'-ssRNA virus), which belongs to the genus Bymovirus of the family Potyvirdae. The protein synthesis of the ' + '-ssRNA virus is completely dependent on the translation machinery of the host cell, and the virus has a high mutation rate that quickly meets the needs of controlling the host cells [14]. The fungal vector carrying the BYMD virus can survive in the soil for more than 10 years and remain virulent [15]. It is difficult to control the disease by crop rotation or chemical application [16-19].

A total of 22 resistance genes to BYMD were mapped on seven chromosomes in barley. Among them, rym4 and rym5 were located on the terminal of chromosome $3 \mathrm{H}$, encoding the eukaryotic translation initiation factor $4 \mathrm{E}(e I F 4 E)$, which were technically the first cloned resistance genes to BYMD. Another Four alleles of eIF4E, rym6, rym10, rym HOR4224, rym HOR3298, were identified in cultivated barley from East Asia [9]. Plant disease tolerance was obtained through an amino acid mutation in the coding region of eIF4E, which suppresses the binding with the viral genome-linked protein (VPg) protein of the virus and terminates the virus translation process [20,21]. However, the resistance of rym4 and rym5 which were widely used in European breeding for years has been overcome by new virus strains [22, 23]. Another cloned resistance gene rym $1 / 11$ from 'Mokusekko 3' was located on chromosome $4 \mathrm{H}$, which belongs to the deletion mutation haplotype of the protein disulfide isomerase like 5-1 (PDIL5-1). The loss of function of PDIL5-1 destroys the correct translation process of the virus in host plants, and the plants gain resistance [24]. The disease resistance of rym1/11 has also been overcome by the new virus strains, and the variety which carries the gene independently showed mild susceptibility [25].
In addition to cloned eIF4E and PDIL5-1, rym7 [26], $\operatorname{Rym}_{16}{ }^{H B}$ [27, 28], Rym17 [29] and Rym14 ${ }^{H B}$ [4] have been fine-mapped to a small region on chromosome $1 \mathrm{H}$, $2 \mathrm{H}, 3 \mathrm{H}$, and $6 \mathrm{H}$, respectively. The remaining $10 \mathrm{BYMD}-$ resistant genes rym8 [30], rym9 [31], rym12 [32], rym13 [33], rym18 [29], rym3 [34], Un-designated [35], rym15 [36], rym2 [32] and rym7t [37] have been preliminarily mapped.

Like many other crops, much genetic resource for biotic stress resistance in barley was lost during domestication, though wild barley is rich in genetic resources [38]. Once the disease-resistant genes are identified from wild barley, the breeding of resistance barley varieties can be accelerated by molecular marker assisted selection system [39]. For instance, resistance genes for barley powdery mildew $[40,41]$ and barley spot blotch were discovered from wild barley [42]. However, among all the resistance genes to BYMD, only Rym $14^{H B}$ and Rym $16^{H B}$ were derived from Hordeum bulbosum and others were derived from cultivated barley. In this study, novel QTL contributing to BYMD resistance was discovered from wild barley, which laid a foundation for the enrichment of yellow-mosaic resistance genetic resources and resistance breeding.

\section{Results \\ Evaluation of resistance to BYMD in parents and DH populations}

The standardized area under disease progress stairs (sAUDPS) and best linear unbiased predictions (BLUPs) of the resistant parent SRY01 in all environments were significantly lower than those of the susceptible parent Gairdner (Table 1 The sAUDPS score of BYMD in parents and DH population in each trial.and. Table S2. The disease grade of BYMD of parents and $\mathrm{DH}$ population in each investigation period). The analysis of variance (ANOVA) showed the effects of 'Genotype', those of 'Genotype $\times$ Year', as well as those of 'Genotype $\times$ Site' were reached to a significant level (. Table S3. ANOVA of sAUDPS score), indicating that the BYMD was not only controlled by genetic factors but also influenced by

Table 1 The sAUDPS score of BYMD in parents and DH population in each trial

\begin{tabular}{lllllll}
\hline Trial & \multicolumn{2}{l}{ Mean of parents } & & \multicolumn{2}{l}{ DH lines } & \\
\cline { 2 - 3 } & SRY01 & Gairdner & & Mean & Range & CV (\%) \\
\hline 2019YZ & 0.02 & 2.18 & & 0.79 & $0.00-2.22$ & $79.23 \%$ \\
2019YC & 0.60 & 1.99 & & 1.43 & $0.10-2.79$ & $37.48 \%$ \\
2020YZ & 0.27 & 2.55 & & 0.90 & $0.00-2.22$ & $86.53 \%$ \\
2020YC & 0.44 & 2.49 & & 1.25 & $0.00-2.53$ & $59.71 \%$ \\
BLUPS & 0.41 & 2.18 & & 1.09 & $0.16-2.13$ & $48.89 \%$ \\
\hline
\end{tabular}


environmental factors represented by year and site. sAUDPS was significantly correlated between the environments and positively correlated with BLUPs (Fig. 1).

In the DH population, the sAUDPS score showed a continuous distribution (Fig. 2), indicating that BYMD was a quantitative trait controlled by multiple genes.

\section{Construction of linkage map and analysis of collinearity}

After filtering the undesirable markers, 5210 high-quality SNP markers were used to construct a linkage map. The total length of the linkage map was $1007.07 \mathrm{cM}$ (. Table S4. The distribution of single nucleotide polymorphism (SNP) markers on chromosomes of the DH population). We aligned the linkage map to the IBSC_v2 (International barley sequencing consortium) reference genome and found that there was good collinearity between the linkage map and the actual physical map except for chromosome $1 \mathrm{H}$ and $2 \mathrm{H}$ (Supplementary Material 5), laying the foundation for identifying candidate genes.

\section{QTL mapping}

Six significant QTL have been identified when analyzing the sAUDPS score and BLUPs with the multiple QTL mapping (MQM) (Table 2 QTL for sAUDPS and BLUPs identified in the DH population). These QTL were mapped on chromosomes $1 \mathrm{H}(q R Y M-1 H), 2 \mathrm{H}(q R Y M-$ $2 \mathrm{Ha}$ and $q R Y M-2 H b), 3 \mathrm{H}(q R Y M-3 H), 5 \mathrm{H}(q R Y M-5 H)$, and $7 \mathrm{H}(q R Y M-7 H)$ (Fig. 3).
There was a stable QTL $(q R Y M-1 H)$ on chromosome $1 \mathrm{H}$, which was detected by the sAUDPS score and BLUPs in all environments, explaining phenotypic variation from 8.80 to $19.80 \%$.

Two QTL were identified on chromosome $2 \mathrm{H}$. $q R Y M$ $2 \mathrm{Ha}$ was identified on the middle of the chromosome which could be detected in all environments, explaining phenotypic variation from 9.30 to $17.80 \%$. Near the end of chromosome $2 \mathrm{H}$, there was a QTL $q R Y M-2 \mathrm{Hb}$ detected only in Yancheng (2019YC, 2020YC, and YCBLUPs), and explained 17.30 to $22.10 \%$ of the phenotypic variation.

At the end of chromosome $3 \mathrm{H}$, one minor QTL $(q R Y M-3 H)$ was detected in Yangzhou (2019YZ, 2020YZ, and YZ-BLUPs) and BLUPs determined 5.60 to $8.10 \%$ of phenotypic variation.

The QTL $q R Y M-5 H$ detected only in Yangzhou (2019YZ, 2020YZ, and YZ-BLUPs) was mapped on chromosome $5 \mathrm{H}$, and $q R Y M-7 H$ on chromosome $7 \mathrm{H}$ was detected only at 1 year in Yangzhou (2020YZ), explaining 9.00 and $6.20 \%$ of phenotypic variation respectively. And both of these two QTL were derived from the susceptible parent Gairdner.

\section{Sequencing of the cloned gene elF4E on chromosome $3 \mathrm{H}$}

Three primers covering the full CDS region of eIF4E were successfully used to amplify this gene from two parents. According to the sequencing results of eIF4E, there was only one coding mutation (G483T) on the third exon between the two parents (Fig. 4). According

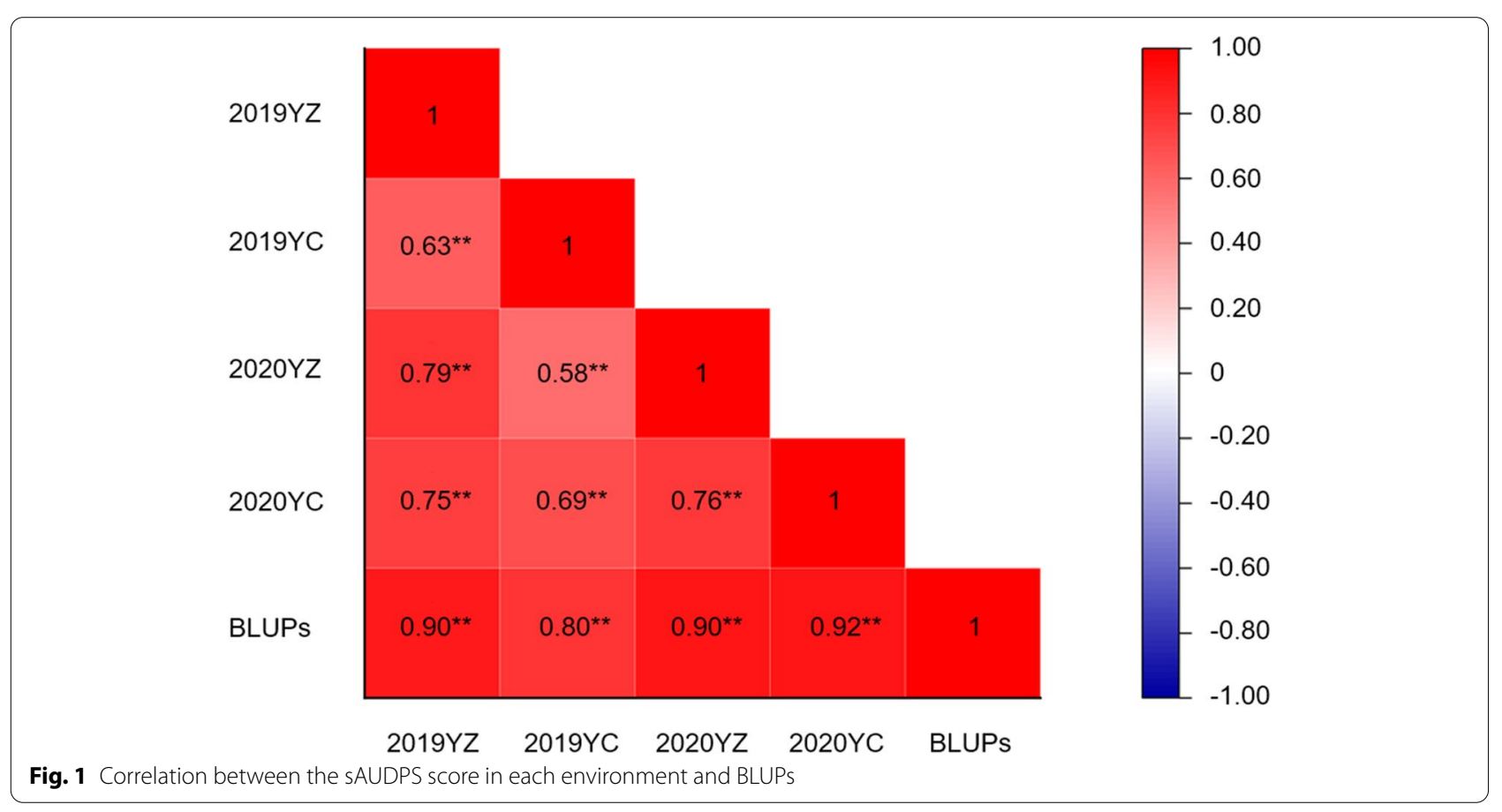



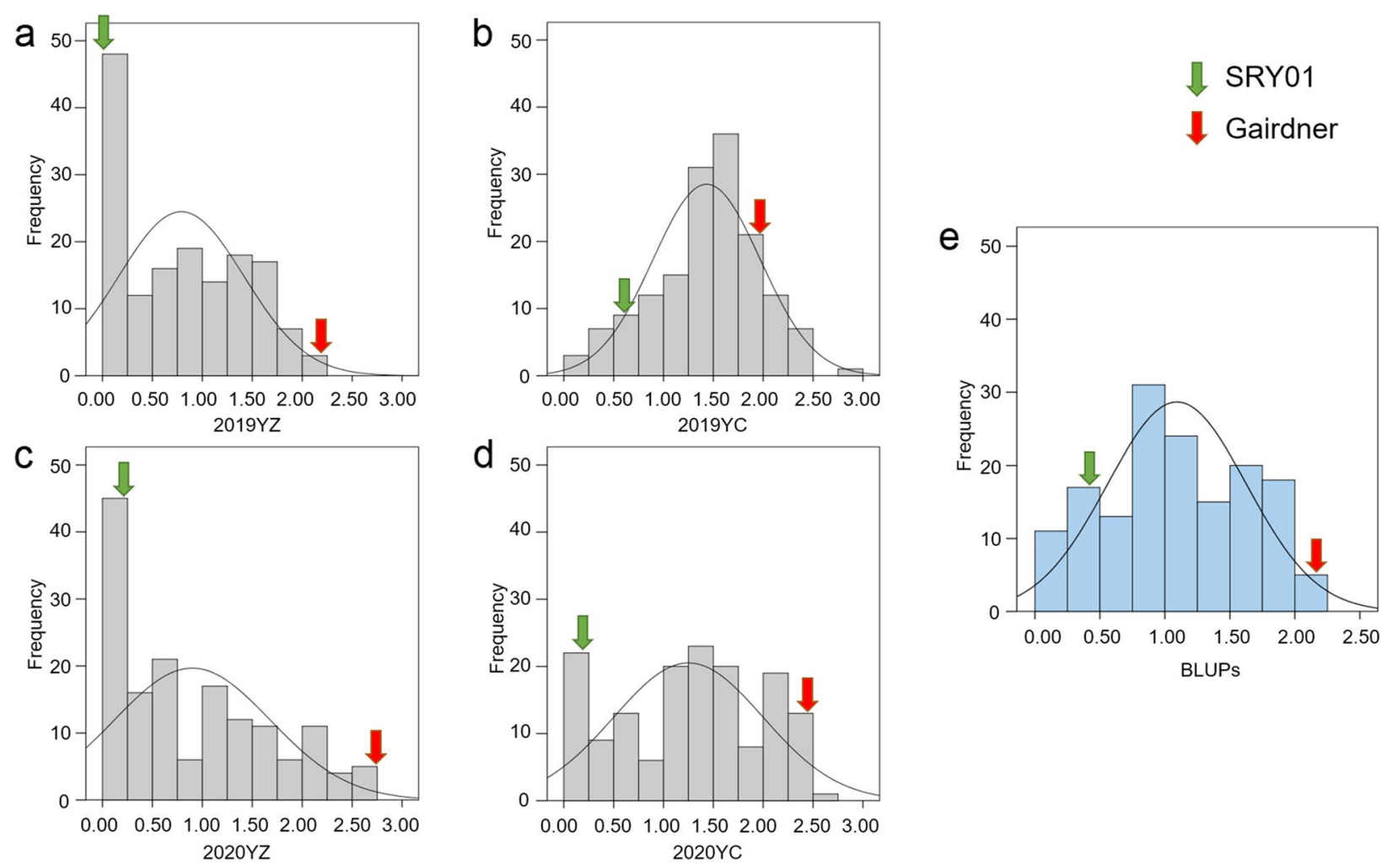

Fig. 2 Frequency distribution of the sAUDPS score in each environment and BLUPS. $\mathbf{a}$, Yangzhou SAUDPS score in 2019. b, Yancheng sAUDPS score in 2019. c, Yangzhou sAUDPS score in 2020. d, Yancheng sAUDPS score in 2020. e, BLUPs for all environments.

to the transcriptional information of eIF4E, this nonsynonymous mutation results in a Gln to His change at the amino acid level (Q161H). SRY01 belongs to haplotype L and Gairdner belongs to haplotype 36 of eIF4E. The two parents did not belong to the resistance haplotype of the cloned gene $[9,43]$.

\section{Developing of InDel markers}

SRY01 and Gairdner were re-sequenced with a sequencing depth of $1.2 \times$. In the physical interval of $q R Y M-2 H a$, there were a total of 540 high-quality polymorphism difference loci between parents at the genomic level, including 451 SNPs and 89 InDels. In this interval, two practical InDel markers named 2H2745 and 2H1958 (. Table S6. Primer information for amplification of InDel in the interval of $q R Y M-2 H a$ on chromosome $2 \mathrm{H}$ ) were successfully developed with polymorphism between parents (Supplementary Material 4).

\section{Discussion}

\section{Effect of environmental factors on BYMD}

The soil-borne BYMD is a serious threat to worldwide winter barley production [9]. The infection of the BYMD virus to plants is a dynamic process affected by environmental temperature [7]. In this study, ANOVA of the sAUDPS score showed that not only the interaction between genotype and site was significant, but also the site effect (Table S3. ANOVA of sAUDPS score), and the sAUDPS score of the DH population in Yangzhou for 2 years was lower than those in Yancheng (Table 1 The sAUDPS score of BYMD in parents and DH population in each trial.), indicating that the disease was more serious in Yancheng. Differences of BYMD virus strains between Yangzhou and Yancheng have been reported $[7,44]$. Two strains of the BYMD virus were isolated in the Yancheng disease nursery, but only one in Yangzhou, and the coat protein and P2 fragments of the three strains were different [45]. In this study, $q R Y M-2 H b$ located on chromosome $2 \mathrm{H}$ was detected only in Yancheng in the 2 years by the sAUDPS score and BLUPs of Yancheng, indicating that $q R Y M-2 H b$ was stable resistance to the Yancheng virus strains specifically. Similarly, $q R Y M-3 H$, $q R Y M-5 H$, and $q R Y M-7 H$ were detected only in Yangzhou. There is a co-evolutionary relationship between the BYMD virus and plant host, which seems to be an 'arms race' $[9,20,21]$. Isolate-specific QTL is an indispensable part of the formation of broad-spectrum resistance in resistant varieties [46], and it is helpful for plant hosts to 
Table 2 QTL for SAUDPS and BLUPs identified in the DH population

\begin{tabular}{|c|c|c|c|c|c|c|c|}
\hline QTL & Chr. & Trial & LOD & PVE (\%) & Additive & QTL Interval & Nearest marker \\
\hline \multirow[t]{7}{*}{ qRYM-1H } & $1 \mathrm{H}$ & 2019YZ & 5.22 & 8.80 & -0.19 & $46.22-53.74$ & SNP0068 \\
\hline & & $2020 Y Z$ & 8.54 & 12.50 & -0.28 & $44.72-52.39$ & SNP0068 \\
\hline & & 2019YC & 6.89 & 14.40 & -0.21 & $44.72-55.04$ & SNP0056 \\
\hline & & 2020YC & 10.13 & 18.90 & -0.34 & $42.15-50.28$ & SNP0056 \\
\hline & & BLUPS & 8.73 & 15.30 & -0.21 & $44.72-53.08$ & SNP0068 \\
\hline & & YZ-BLUPS & 8.22 & 12.40 & -0.21 & $46.22-52.39$ & SNP0068 \\
\hline & & YC-BLUPS & 11.08 & 19.80 & -0.22 & $44.72-50.28$ & SNP0056 \\
\hline \multirow[t]{7}{*}{ aRYM-2Ha } & $2 \mathrm{H}$ & $2019 Y Z$ & 7.08 & 12.30 & -0.23 & $85.86-91.78$ & SNP0582 \\
\hline & & $2020 Y Z$ & 8.28 & 12.00 & -0.29 & $85.86-91.78$ & SNP0582 \\
\hline & & 2019YC & 3.72 & 9.30 & -0.17 & $87.28-91.78$ & SNP0583 \\
\hline & & 2020YC & 7.55 & 16.40 & -0.31 & $87.28-91.78$ & SNP0582 \\
\hline & & BLUPS & 9.99 & 17.80 & -0.23 & $85.86-91.78$ & SNP0582 \\
\hline & & YZ-BLUPS & 7.97 & 11.90 & -0.21 & 84.43-91.78 & SNP0582 \\
\hline & & YC-BLUPS & 7.04 & 15.40 & -0.19 & 87.28-92.99 & SNP0582 \\
\hline \multirow[t]{3}{*}{$q R Y M-2 H b$} & $2 \mathrm{H}$ & 2019YC & 9.09 & 20.90 & -0.27 & $153.32-164.03$ & SNP0812 \\
\hline & & 2020YC & 8.05 & 17.30 & -0.34 & $154.55-165.45$ & SNP0812 \\
\hline & & YC-BLUPS & 10.63 & 22.10 & -0.24 & $162.5-164.03$ & SNP0812 \\
\hline \multirow[t]{4}{*}{ qRYM-3H } & $3 \mathrm{H}$ & $2019 Y Z$ & 4.45 & 7.50 & -0.17 & $126.68-128.42$ & SNP2754 \\
\hline & & $2020 Y Z$ & 4.10 & 5.60 & -0.19 & $126.68-128.83$ & SNP2754 \\
\hline & & BLUPS & 4.92 & 8.10 & -0.15 & $126.72-127.51$ & SNP2754 \\
\hline & & YZ-BLUPS & 5.10 & 7.30 & -0.16 & $126.68-127.51$ & SNP2754 \\
\hline \multirow[t]{3}{*}{$q R Y M-5 H^{G}$} & $5 \mathrm{H}$ & 2019YZ & 5.03 & 8.50 & 0.19 & $118.5-122.06$ & SNP4451 \\
\hline & & $2020 Y Z$ & 4.84 & 6.70 & 0.21 & $118.08-121.56$ & SNP4460 \\
\hline & & YZ-BLUPS & 6.21 & 9.00 & 0.18 & $118.5-119.55$ & SNP4460 \\
\hline $9 R Y M-7 H^{G}$ & $7 \mathrm{H}$ & $2020 Y Z$ & 4.67 & 6.20 & 0.21 & $0.01-3.98$ & SNP5411 \\
\hline
\end{tabular}

${ }^{G}$ According to the additive effect, QTL were from Gairdner. The others QTL were from SRY01

obtain sustainable and comprehensive advantages in the race.

Moreover, the optimal temperature for BaYMV infection is $15^{\circ} \mathrm{C}[17,47]$, slightly higher temperature is beneficial for the infection, increasing virus replication and movement from roots to leaves $[8,48]$. According to meteorological data, during the 5 months from barley sowing to the onset of BYMD, the monthly average temperature in Yangzhou in 2020 is higher than that in 2019 (. Table S5. Monthly average temperature of Yangzhou from 2018 to 2020). The higher temperature conditions in YZ2020 led to the aggravation of BYMD (Table 1 The sAUDPS score of BYMD in parents and DH population in each trial.). This might explain why $q R Y M-7 H$ was only detected in YZ2020.

\section{A novel QTL contributing resistance to BYMD from wild barley}

BYMD virus strains mutate rapidly, and the resistance of varieties (lines) carrying a single resistance gene can be easily overcome [31]. The varieties containing multiple resistance genes such as 'Mokusekko 3' (rym1 and rym5)
[49], 'Chikurin Ibaraki 1' (rym15 and Un-designated) [35, 36] and 'PK23-2' (Rym17 and rym18) [29] can resist most strains of BYMD, sustainably surviving from the disease in the nursery.

In this study, four resistance-related QTL were identified in SRY01, a wild barley with high resistance to BYMD in all environments. Among resistance-related QTL, there is no resistance-conferring gene to BYMD near $q R Y M-2 H a$ which was detected a total of 7 times by MQM in all environments. In summary, $q R Y M-2 H a$ is a novel major QTL related to BYMD resistance. The confidence interval of $q R Y M-2 H a$ is $85.856-91.781 \mathrm{cM}$ in genetics, overlapping the physical interval of about 23.78 Mbp (613.472-637.249 Mbp in physics). According to the barley reference genome IBSC_v2, there are 242 annotated genes in this interval. After further searching the function of each gene on the BARLEX [50], nine annotated genes were found to be related to plant disease resistance (. Table S7. Genes related to resistance in the interval of $q R Y M-2 H a$ on chromosome $2 \mathrm{H}$ ). Among them, three adjacent genes (HORVU2Hr1G086860 starts at $625.19 \mathrm{Mbp}$, HORVU2Hr1G087370 starts at 627.20 


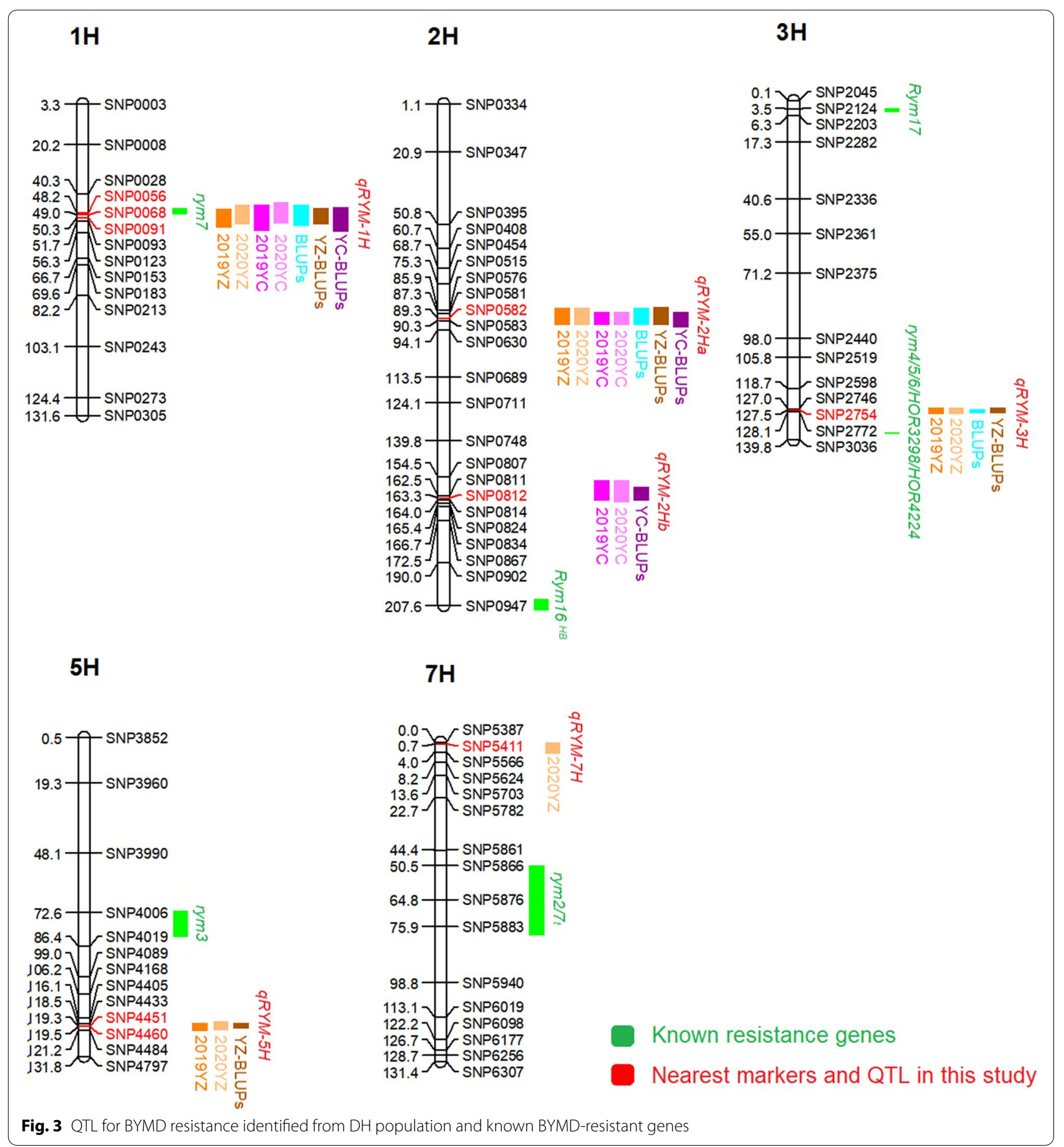

Mbp. and HORVU2Hr1G087500 starts at $628.42 \mathrm{Mbp}$ ) were annotated as leucine-rich repeat receptor-like protein kinase family protein, which is associated with resistance proteins [51] which may present the candidate genes for $q R Y M-2 H a$. At the genomic level, 89 indels were identified in the physical interval of $q R Y M-2 H a$ between parents. The development of these practical InDels markers such as $2 \mathrm{H} 2745$ and $2 \mathrm{H} 1958$ will lay the foundation for molecular marker-assisted selection breeding and the subsequent fine mapping.

\section{Comparison of QTL with known BYMD-resistant genes}

Up to now, only one gene, $r y m 7$, has been mapped on chromosome $1 \mathrm{H}$ [7]. This gene was fine-mapped through 


\section{Hv-eIF4E} chr3H:689854744-689854760

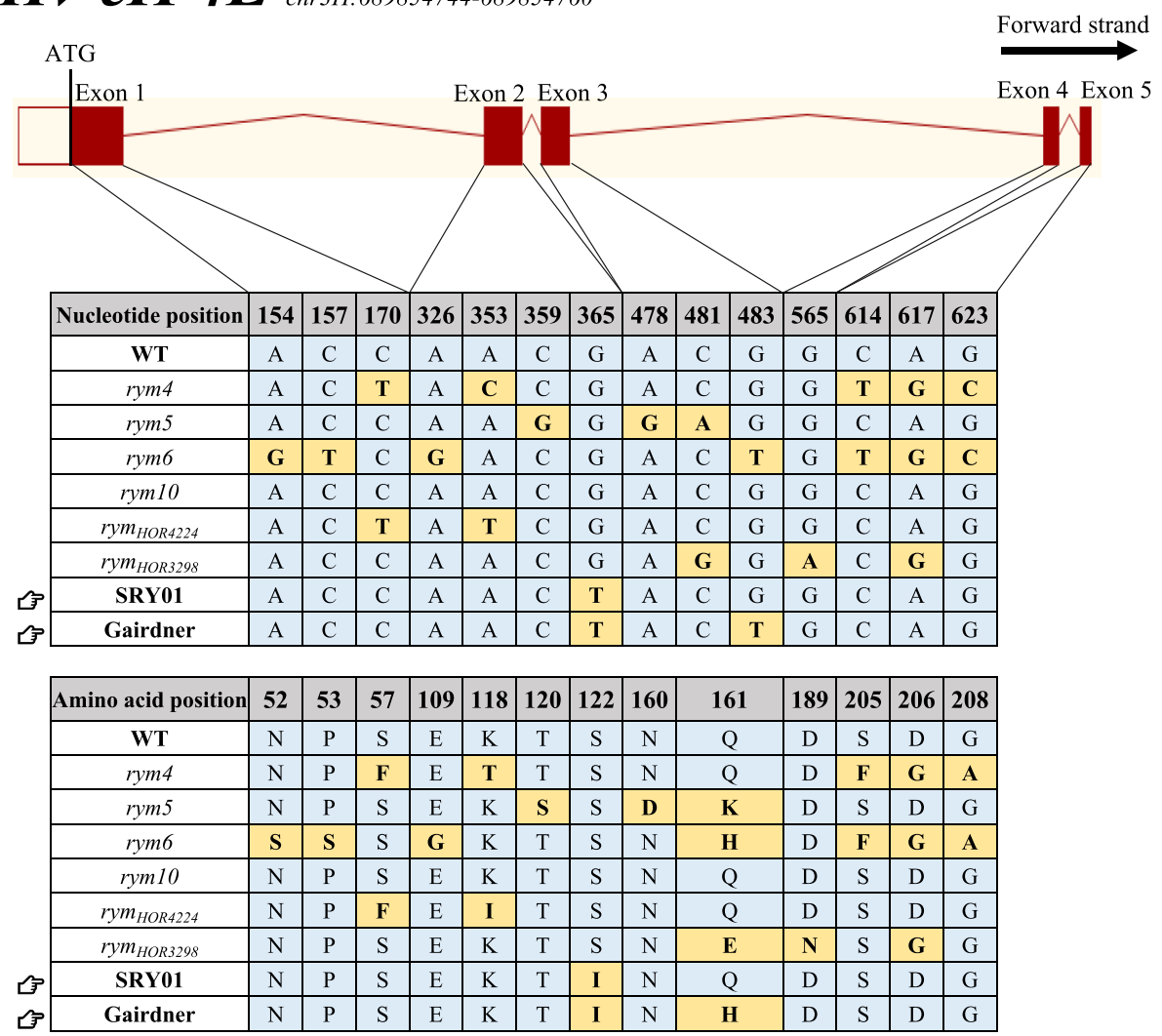

Fig. 4 Haplotype analysis of the cloned gene elF4E on chromosome $3 \mathrm{H}$

linkage analysis based on $53 \mathrm{DH}$ lines constructed from the disease-resistant variety HHOR3365 and the susceptible variety Igri. The phenotype was obtained by mechanical inoculation of the DH lines with the BaMMV strain, meanwhile, a linkage map constructed by combining 350 molecular markers specifically designed on chromosome $1 \mathrm{H}$ was used [26]. Bamg347, one of the nearest markers of rym7, had a physical location of $173.68 \mathrm{Mbp}$, which was closest to SNP0060 (172.96 Mbp in physics, $48.16 \mathrm{cM}$ in genetics). SNP0060 was in the center of the confidence interval of $q R Y M-1 H$ in our work, indicating there was an overlap between $r y m 7$ and $q R Y M-1 H$ (Fig. 3). We used different materials and methods to locate the resistance loci in the same region with previous researchers.

There is only one BYMD-resistant gene Rym $16^{H B}$ delivered from Hordeum bulbosum was located on chromosome $2 \mathrm{H}$, and its closest linkage marker was MWG949 (766.31 Mbp in IBSC or 664.04 Mbp in Morex v3.0) [27]. In this study, two QTL were mapped on chromosome $2 \mathrm{H}$, and the nearest marker were SNP0582 (621.11 Mbp in in IBSC or 545.19 Mbp in Morex v3.0) and SNP0812 (723.86 Mbp in IBSC or $630.15 \mathrm{Mbp}$ in Morex v3.0) respectively, which were far away from $R y m 16^{H B}$ (the minimum distance difference was about $42 \mathrm{Mbp}$ in IBSC or $34 \mathrm{Mbp}$ in Morex v3.0). Therefore, $q R Y M-2 H a$ and $q R Y M-2 H b$ on chromosome $2 \mathrm{H}$ identified in this study present new loci related to disease resistance.

$q R Y M-3 H$ was located at the end of chromosome $3 \mathrm{H}$, and its nearest marker SNP2754 (637.29 Mbp in physics) was close to the cloned gene eIF4E (689.85 Mbp in physics) by a distance of about $52 \mathrm{Mbp}$ in physics or $10 \mathrm{cM}$ in genetic position. To determine whether $q R Y M-3 H$ is the cloned gene, the eIF4E of the two parents were sequenced and compared. The results showed that there was only one SNP between the parents, resulting in one amino acid change. Through the comparison of the eIF4E CDS sequence, the two parents did not belong to the haplotype of the known BYMD-resistant gene (Fig. 4) [43]. However, $q R Y M$ $3 H$ was detected in Yangzhou and BLUPs, and its LOD value and contribution rate were low. It was speculated that $q R Y M-3 H$ was a new minor locus that is only resistant to Yangzhou virus strains. In addition, two resistance-related QTL $q R Y M-5 H$ and $q R Y M-7 H$ from susceptible parent Gairdner on the chromosomes $5 \mathrm{H}$ 
and $7 \mathrm{H}$ were detected only in Yangzhou, both of which were far away from the known disease resistance genes (Fig. 3). Whether these two QTL with lower effects were related to disease resistance remains to be further studied.

\section{Conclusions}

BYMD seriously threatens the production of winter barley. It is critical to identify novel resistance loci that can be used to genetically control BYMD. We used a DH population constructed from cultivated barley and wild barley as the material. After 2 years and two sites of resistance identification, combined with a high-resolution genetic map, we used the classical QTL mapping strategy to mine loci related to BYMD. Two major QTL for the resistance were identified. One of them was located in the same position to the known $\mathrm{R}$ gene rym7. Another one detected on chromosome $2 \mathrm{H}$ was not reported before and the resistance allele was from the wild barley parent. It is the first report on BYMD-resistant QTL from wild barley accessions (Hordeum vulgare spp. spontaneum). Based on biparental re-sequencing data, closely linked InDel markers for this novel major QTL were developed which could be used for MAS in barley breeding.

\section{Methods}

\section{Plant materials and growth conditions}

A total of $154 \mathrm{~F}_{1}$-derived doubled haploid (DH) lines generated from a cross between SRY01 and Gairdner were used in this study. The female parent SRY01 is a wild tworow barley (Hordeum vulgare spp. spontaneum) resistant to BYMD, and the male parent Gairdner is an Australian two-row malting barley (Hordeum vulgare spp. vulgare) susceptible to BYMD.

In the autumn of 2018 and 2019, the materials were sown in the BYMD nursery in Yangzhou University (Yangzhou, Jiangsu, China, $32^{\circ} \mathrm{N}, 119^{\circ} \mathrm{E}$ ) and Jiangsu Coastal Agricultural Sciences Institute (Yancheng, Jiangsu, China, $33^{\circ} \mathrm{N}, 120^{\circ} \mathrm{E}$ ) at the same time. Ten seeds of parental varieties and $\mathrm{DH}$ lines were sown in a $1.0 \mathrm{~m}$ row with $0.2 \mathrm{~m}$ of inter-row spacing and repeated three times separately.

\section{Evaluation of resistance to BYMD}

The disease grade of the materials was qualitatively assessed from 0 to 4 [52]:

0 , no visible symptom.

1 , a small amount of pale-green chlorotic spots emerges, and the area of the yellow mosaic of new leaves is $<5 \%$.

2 , the number of chlorotic spots is more, the shortstriped spots which parallel to the leaf veins appear, and the area of the yellow mosaic of new leaves is $>5 \%$ and $<25 \%$.

3 , the area of chlorotic spots expanded significantly and the short-striped spots developed into kite-shape patches, the area of the yellow mosaic of new leaves is $>25 \%$ and $<50 \%$ and the height of infected plant decreased slightly.

4 , the leaves turn yellow, the plants dwarf or even wither, and the area of the yellow mosaic of new leaves is $>75 \%$.

In the spring of 2019, four periods of investigation in Yangzhou were conducted on February 19, February 25, March 3, and March 10. Three periods of investigation in Yancheng were conducted on February 19, February 25, and March 5. In the spring of 2020, five periods of investigation in Yangzhou were conducted on February 9, February 18, February 24, March 4, and March 16. Five periods of investigation in Yangzhou were conducted on February 2, February 9, February 16, February 23, and March 1.

The disease grade data of the investigation was analyzed using Microsoft Excel 2019 software. The standardized area under disease progress stairs (sAUDPS) was used for resistance evaluation. This index can combine multiple observations of disease progress into a single value [53], and is not affected by the total investigation times. The index is calculated as follows:

$$
\left(\mathrm{sAUDPS}=\left\{\sum_{i=1}^{n-1}\left[\frac{y_{i}+y_{i+1}}{2} \times\left(t_{i+1}-t_{i}\right)\right]+\left[\frac{y_{1}+y_{n}}{2} \times \frac{D}{n-1}\right]\right\} \times \frac{n-1}{D n}\right.
$$

In this formula, the $n$ is the total number of investigations, the $D=t_{n}-t_{1}$ is the total investigation times, and the disease grade and date of the $i$-th investigation period are expressed by $y_{i}$ and $t_{i}$ respectively. The sAUDPS score of Yangzhou in 2019, Yangzhou in 2020, Yancheng in 2019, and Yancheng in 2020 are expressed by 2019YZ, 2020YZ, 2019YC, and 2020YC respectively.

The best linear unbiased prediction (BLUP) [54] Marker-assisted selection using best linear unbiased prediction on the sAUDPS score of the four environments were obtained using the lme4 package of the $R$ [55]. In addition, BLUP was used to fit the phenotypes of the same location in different years, and the results were expressed by YZ-BLUPs and YC-BLUPs respectively. Use IBM SPSS Statistics 22 software for further descriptive statistics, ANOVA, and Pearson correlation analysis [56].

\section{Genotyping, map construction, and QTL mapping}

DNA extraction and genotyping were performed as described in previous publications [57]. Two parental varieties and $154 \mathrm{DH}$ lines were genotyped with DArTSeq (http://www.diversityarrays.com/). SNP markers 
were filtered according to the following criteria: heterozygous markers, markers without polymorphism between parents, and markers with a miss rate of more than $15 \%$ were eliminated. Referring to the methods of previous publications [58], the filtered SNP markers were used to construct a linkage map through MSTmap software [59]. The linkage map was aligned with the reference genome through OriginPro 9.1 software [60]. QTL mapping was conducted with MapQTL v6.0 software [61]. The naming of QTL follows the naming principle of McCouch et al. [62]. Linkage maps showing the QTL positions were drawn by using MapChart v2.32 software [63].

\section{Anchoring of known genes on the linkage map}

To determine whether the QTL mapped in this study were the same as reported resistance genes of BYMD, sequence information of near linkage or flank markers of 22 reported resistance genes were collected. The physical positions of these markers in the barley IBSC reference genome and were obtained by the BLASTN (http:// plants.ensembl.org/Hordeum_vulgare/Tools/Blast). The SNP markers which were closely linked to the reported disease resistance genes were anchored to the linkage map based on the physical location. Barley reference genome has been updated in 2021, and sequence information can be obtained online [64]. In order to more accurately determine the relationship between our two novel QTL and the physical location of known genes on chromosome $2 \mathrm{H}$, BLASTN was performed in the Barley pseudomolecules Morex v3.0 reference genome (https:// galaxy-web.ipk-gatersleben.de/).

\section{Sequencing of the cloned gene rym4}

The cloned genes rym4, rym5, rym6, rym10, rym HOR4224, $_{1}$ and rym $_{\text {HOR3298 }}$ belong to different haplotypes of eIF4E on chromosome $3 \mathrm{H}$. Primers used for sequencing of eIF4E haplotypes were derived from previous publications (Table S1). The CDS region of eIF4E was amplified in SRY01 and Gairdner as referring to previous publications $[9,65,66]$. Then the amplified product was loaded on the agarose gel, and the bands which fit the product size were sent to BGI-Genomics (Shenzhen, China) for Sanger sequencing.

\section{Developing InDel markers from resequencing data}

To serve resistance breeding, polymorphic molecular markers linked to resistance loci were developed. Economic low-depth resequencing was used to analyze the differences between parents at the genomic level. The DNA of the two parents were sent to Berry Genomics Co. Ltd. (Beijing, China) for resequencing by using the Illumina HiSeq-PE150 high-throughput sequencing platform. The Illumina clean reads provided by the sequencing company were mapped onto the assembled reference IBSC_v2 genome [67] with the BurrowsWheeler Aligner [68] using the default parameters. The SAMtools mpileup program was used to assess variant sites [69]. TBtools software was used to extract sequence information near the variant sites [70]. InDel markers were designed using the Primer 3.0 (https://bioinfo.ut. ee/primer3-0.4.0/) according to the variant sites. The InDel markers were used to PCR-amplify DNA of both parental genotypes in a final volume of $10 \mu \mathrm{L}$, containing $40 \mathrm{ng}$ genomic DNA, $0.2 \mu \mathrm{M}$ forward and reverse primers, and $5 \mu \mathrm{L} 2 \times$ Taq Master Mix (Vazyme, Nanjing, China). Easy-to-operate PCR amplification was performed with $3 \mathrm{~min}$ at $95^{\circ} \mathrm{C}$ for initial denaturation, followed by 34 cycles of $15 \mathrm{~s}$ at $95^{\circ} \mathrm{C}, 20 \mathrm{~s}$ at $58^{\circ} \mathrm{C}, 15 \mathrm{~s}$ at $72^{\circ} \mathrm{C}$, and finally one step of $10 \mathrm{~min}$ at $72^{\circ} \mathrm{C}$. The amplified product was detected in $4.0 \%$ agarose.

\section{Abbreviations \\ BYMD: Barley yellow mosaic disease; BaYMV: Barley yellow mosaic virus; BaMMV: Barley mild mosaic virus; DH: Doubled haploid; QTL: Quantitative trait loci;'+'-'-ssRNA virus: Positive-sense single-stranded RNA virus; elF4E: Eukaryotic translation initiation factor 4E; PDIL5-1: Protein disulfide isomerase like 5-1; sAUDPS: The standardized area under disease progress stairs; BLUP: Best linear unbiased prediction; BLUPs: Best linear unbiased predictions; IBSC: International barley sequencing consortium; MQM: Multiple QTL mapping; YZ: Yangzhou, China; YC: Yancheng, China; Gln: Glutamine; His: Histidine; ANOVA: Analysis of variance.}

\section{Supplementary Information}

The online version contains supplementary material available at https://doi. org/10.1186/s12870-021-03321-x.

Additional file 1: Table S1. Primer information for amplification of HvelF4E. Table S2. The disease grade of BYMD of parents and DH population in each investigation period. Table S3. ANOVA of sAUDPS score. Table S4. The distribution of single nucleotide polymorphism (SNP) markers on chromosomes of the DH population. Table S5. Monthly average temperature of Yangzhou from 2018 to 2020. Table S6. Primer information for amplification of InDel in the interval of $q R Y M-2 H a$ on chromosome $2 \mathrm{H}$. Table S7. Genes related to resistance in the interval of $q \mathrm{RYM}-2 \mathrm{Ha}$ on chromosome $2 \mathrm{H}$.

\section{Acknowledgements}

We thank Professor Meixue Zhou from the University of Tasmania, Australia for generously providing the population seed used for this project.

\section{Authors' contributions}

RX design experiment project. YP was responsible for the phenotypic data of the survey, as well as chart production and manuscript writing. JZ wrote and edited the manuscript. YH and $\mathrm{MZ}$ assisted in data processing and chart production. $\mathrm{CL}$ and BG assisted in the phenotype collection of the Yangzhou survey. HS and XX assisted in the phenotype collection of the Yancheng survey. All authors read and approved the final manuscript.

\section{Funding}

This work was supported by the Key Technologies Research and Development Program of China (2018YFD1000700 and 2018YFD1000703), National Modern Agriculture Industry Technology System,China (CARS-05), Jiangsu University Advantage Discipline Construction Project, Jiangsu Agricultural Science and Technology Innovation Fund (CX(19)3062). 


\section{Availability of data and materials}

The phenotype data of the $\mathrm{DH}$ population in this study are in Additional file 1 (Supplementary Material 1). The disease grade of BYMD of parents and DH population in each investigation period and ANOVA of SAUDPS score are in Supplementary. Table S2. The disease grade of BYMD of parents and DH population in each investigation period and Supplementary. Table S3. ANOVA of sAUDPS score, respectively. The genotype data including the physical and linkage map location of SNP markers are in Additional file 2 (Supplementary Material 2). The distribution of SNP markers on chromosomes of the DH population is listed in Supplementary. Table S4. The distribution of single nucleotide polymorphism (SNP) markers on chromosomes of the DH population. Primer information for amplification of HvelF4E and InDel in the interval of aRYM-2Ha on chromosome $2 \mathrm{H}$ is in Supplementary Table S6. Primer information for amplification of InDel in the interval of $9 R Y M-2 H a$ on chromosome $2 \mathrm{H}$, respectively. The sequences of the amplified HvelF4E of the two parents are listed in Additional file 3 (Supplementary Material 3, in FASTA formart). The InDel markers were used to amplify the genotype of the parents in agarose gel are shown in Additional file 4 (Supplementary Material 4). The collinearity of linkage map and the physical map was shown in Additional file 5 (Supplementary Material 5). The monthly average temperature of Yangzhou from 2018 to 2020 is listed in Supplementary. Table S5. Monthly average temperature of Yangzhou from 2018 to 2020 according to the meteorology database from http://www.nmc.cn/. Genes related to resistance in the interval of qRYM-2Ha on chromosome $2 \mathrm{H}$ are given in Supplementary. Table S7. Genes related to resistance in the interval of qRYM-2Ha on chromosome $2 \mathrm{H}$, and the gene annotation information is accessible through BARLEYX online (https://apex.ipk-gatersleben.de/apex/f?p=284: 10). The Ime 4 package of the $R$ is available from https://cran.r-project.org/web/ packages/lme4/index.html. The published barley reference genome is available from ftp://ftp.ensemblgenomes.org/pub/plants/release-48/fasta/hordeum_ vulgare/dna/.

\section{Declarations}

Ethics approval and consent to participate

Not applicable.

\section{Consent for publication}

All authors agree to publish in BMC Plant Biology.

\section{Competing interests}

The authors declare that they have no competing interests.

\section{Author details}

${ }^{1}$ Key Laboratory of Plant Functional Genomics of the Ministry of Education / Jiangsu Key Laboratory of Crop Genomics and Molecular Breeding / Jiangsu Co-Innovation Center for Modern Production Technology of Grain Crops / Institutes of Agricultural Science and Technology Development, Yangzhou University, Yangzhou 225009, Jiangsu, China. ${ }^{2}$ Jiangsu Institute for Seaside Agricultural Sciences and Yancheng Academy of Agricultural Science, Yancheng 224002, Jiangsu, China.

Received: 22 September 2021 Accepted: 8 November 2021 Published online: 25 November 2021

\section{References}

1. Newman CW, Newman RK. A brief history of barley foods. Cereal Foods World. 2007;51:4-7.

2. Food and Agriculture Organization of the United Nations (2019) FAOSTAT. http://www.fao.org/faostat/en/\#data/QC. Accessed May 2021.

3. Kühne T. Soil-borne viruses affecting cereals-known for long but still a threat. Virus Res. 2009;141:174-83.

4. Pidon H, Wendler N, Habekuß A, Maasberg A, Ruge B. High-resolution mapping of Rym $14 \mathrm{Hb}$, a wild relative resistance gene to barley yellow mosaic disease. Theor Appl Genet. 2020;134:823-33.

5. Chen Z, Mao S, Zhang W, Fan X, Wu W, Liu C, et al. Rapid visual detection method for barley yellow mosaic virus using reverse transcription loopmediated isothermal amplification (RT-LAMP). Plant Dis. 2020. https://doi. org/10.1094/PDIS-06-20-1216-RE.
6. Plumb RT, Lennon EA, Gutteridge RA. The effects of infection by barley yellow mosaic virus on the yield and components of yield of barley. Plant Pathol. 1986;35:314-8.

7. Jiang C, Kan J, Ordon F, Perovic D, Yang P. Bymovirus-induced yellow mosaic diseases in barley and wheat: viruses, genetic resistances and functional aspects. Theor Appl Genet. 2020;133(3):1-18.

8. Chen J. Progress and prospects of studies on Polymyxa graminis and its transmitted cereal viruses in China. Prog Nat Sci. 2005;15:481-90.

9. Yang P, Habekuß A, Hofinger BJ, Kanyuka K, Kilian B, Graner A, et al. Sequence diversification in recessive alleles of two host factor genes suggests adaptive selection for bymovirus resistance in cultivated barley from East Asia. Theor Appl Genet. 2017;130:331-44.

10. Huth W, Adams MJ. Barley yellow mosaic virus (BaYMV) and BaYMV-M: two different viruses. Intervirology. 1990;31:38-42.

11. Werner K, Friedt W, Ordon F. Localisation and combination of resistance genes against soil-borne viruses of barley (BaMMV, BaYMV) using doubled haploids and molecular markers. Euphytica. 2007;158:323-9.

12. Schenk PM, Antoniw JF, Batista M, Jacobi V, Adams MJ, Steinbiss HH. Movement of barley mild mosaic and barley yellow mosaic viruses in leaves and roots of barley. Ann Appl Biol. 1995;126:291-305.

13. Ward E, Kanyuka K, Motteram J, Kornyukhin D, Adams MJ. The use of conventional and quantitative real-time PCR assays for Polymyxa graminis to examine host plant resistance, inoculum levels and intraspecific variation. New Phytol. 2005; 165:875-85.

14. Miras M, Allen Miller W, Truniger $V$, Aranda MA. Non-canonical translation in Plant RNA viruses. Front Plant Sci. 2017;8:494-513.

15. Chen J, Swaby AG, Adams MJ, Yili R. Barley mild mosaic virus inside its fungal vector, Polymyxa graminis. Ann Appl Biol. 1991;118:615-21.

16. Kanyuka K, Ward E, Adams MJ. Polymyxa graminis and the cereal viruses it transmits: a research challenge. Mol Plant Pathol. 2003;4:393-406.

17. Nomura K, Kashiwazaki S, Hibino H, Inoue T, Nakata E, Tsuzaki Y, et al. Biological and serological properties of strains of barley mild mosaic virus. J Phytopathol. 1996;144:103-7.

18. Zheng T, Cheng Y, Chen JP, Antoniw JF, Adams MJ. The occurrence of barley mild mosaic virus (BaMMV) in China and the nucleotide sequence of its coat protein gene. J Phytopathol. 1999;147:229-34.

19. Nishigawa H, Hagiwara T, Yumoto M, Sotome T, Kato T, Natsuaki T. Molecular phylogenetic analysis of barley yellow mosaic virus. Arch Virol. 2008;153:1783-6.

20. Stein N, Perovic D, Kumlehn J, Pellio B, Stracke S, Streng S, et al. The eukaryotic translation initiation factor $4 \mathrm{E}$ confers multiallelic recessive Bymovirus resistance in Hordeum vulgare (L.). Plant J. 2005;42:912-22.

21. Charron C, Nicolaï M, Gallois JL, Robaglia C, Moury B, Palloix A, et al. Natural variation and functional analyses provide evidence for co-evolution between plant elF4E and potyviral VPg. Plant J. 2008;54:56-68.

22. Habekuss A, Humbroich K, Jacobi A, Cselenyi L, Leroy N, Friedt W, et al. Genotypes resistant to new strains of barley mild mosaic virus. BaMMVSil): BaMMV-Teik; 2008.

23. Rolland M, Villemot J, Marais A, Theil S, Faure C, Cadot V, et al. Classical and next generation sequencing approaches unravel Bymovirus diversity in barley crops in France. PLoS One. 2017;12:1-16.

24. Yang P, Lüpken T, Habekuss A, Hensel G, Steuernagel B, Kilian B, et al. Protein disulfide isomerase like $5-1$ is a susceptibility factor to plant viruses. Proc Natl Acad Sci. 2014;111:2104-9.

25. Okada Y, Kanatani R, Arai S, Ito K. Interaction between barley yellow mosaic disease-resistance genes rym 1 and rym5, in the response to BaYMV strains. Breed Sci. 2004;54:319-25.

26. Yang P, Perovic D, Habekuß A, Zhou R, Graner A, Ordon F, et al. Genebased high-density mapping of the gene rym 7 conferring resistance to barley mild mosaic virus (BaMMV). Mol Breed. 2013;32:27-37.

27. Ruge-Wehling B, Linz A, Habekuß A, Wehling P. Mapping of Rym $16 \mathrm{Hb}$ the second soil-borne virus-resistance gene introgressed from Hordeum bulbosum. Theor Appl Genet. 2006;113:867-73.

28. Johnston PA, Meiyalaghan V, Forbes ME, Habekuß A, Butler RC, Pickering R. Marker assisted separation of resistance genes Rph22 and Rym 16 $\mathrm{Hb}$ from an associated yield penalty in a barley: Hordeum bulbosum introgression line. Theor Appl Genet. 2015;128:1137-49.

29. Kai H, Takata K, Tsukazaki M, Furusho M, Baba T. Molecular mapping of Rym 17, a dominant and rym 18 a recessive barley yellow mosaic virus (BaYMV) resistance genes derived from Hordeum vulgare L. Theor Appl Genet. 2012;124:577-83. 
30. Bauer E, Weyen J, Schiemann A, Graner A, Ordon F. Molecular mapping of novel resistance genes against barley mild mosaic virus (BaMMV). Theor Appl Genet. 1997;95:1263-9.

31. Werner K, Friedt W, Ordon F. Strategies for pyramiding resistance genes against the barley yellow mosaic virus complex (BaMMV, BaYMV, BaYMV-2). Mol Breed. 2005;16:45-55.

32. Gotz R, Friedt W. Resistance to the barley yellow mosaic virus complex - differential genotypic reactions and genetics of BaMMV-resistance of barley (Hordeum vulgare L.). Plant Breed. 1993;111:125-31.

33. Werner K, Rönicke S, Le Gouis J, Friedt W, Ordon F. Mapping of a new BaMMV-resistance gene derived from the variety "Taihoku A... Zeitschrift fur Pflanzenkrankheiten und Pflanzenschutz. 2003;110:304-11.

34. Saeki K, Miyazaki C, Hirota N, Saito A, Ito K, Konishi T. RFLP mapping of BaYMV resistance gene rym3 in barley (Hordeum vulgare). Theor Appl Genet. 1999;99:727-32

35. Werner K, Friedt W, Laubach E, Waugh R, Ordon F. Dissection of resistance to soil-borne yellow-mosaic-inducing viruses of barley (BaMMV, BaYMV, BaYMV-2) in a complex breeders' cross by means of SSRs and simultaneous mapping of BaYMV/BaYMV-2 resistance of var. "Chikurin Ibaraki 1.." Theor Appl Genet. 2003;106:1425-32.

36. Le Gouis J, Devaux P, Werner K, Hariri D, Bahrman N, Béghin D, et al. rym 15 from the Japanese cultivar Chikurin Ibaraki 1 is a new barley mild mosaic virus (BaMMV) resistance gene mapped on chromosome 6H. Theor Appl Genet. 2004;108:1521-5.

37. Takata K, Kai H, Uchimura Y, Tsukazaki M, Furusho M, Baba T. Selection of DNA markers closely linked to the resistance gene rym7t against barley yellow mosaic disease. Breed Res. 2012;14:43-9.

38. Dai F, Zhang GP. Domestication and improvement of cultivated barley. In: Zhang GP, Li CD, editors. Exploration, identification and utilization of barley Germplasm. Hangzhou: Academic; 2016. p. 1-26.

39. Ellis RP, Forster BP, Robinson D, Handley LL, Gordon DC, Russell JR, et al. Wild barley: a source of genes for crop improvement in the 21st century? J Exp Bot. 2000;51:9-17.

40. Silvar C, Kopahnke D, Flath K, Serfling A, Perovic D, Casas AM, et al. Resistance to powdery mildew in one Spanish barley landrace hardly resembles other previously identified wild barley resistances. Eur J Plant Pathol. 2013;136:459-68.

41. Ames N, Dreiseitl A, Steffenson BJ, Muehlbauer GJ. Mining wild barley for powdery mildew resistance. Plant Pathol. 2015;64:1396-406.

42. Roy JK, Smith KP, Muehlbauer GJ, Chao S, Close TJ, Steffenson BJ. Association mapping of spot blotch resistance in wild barley. Mol Breed. 2010;26:243-56.

43. Yang P, Habekuß A, Ordon F, Stein N. Analysis of bymovirus resistance genes on proximal barley chromosome $4 \mathrm{HL}$ provides the basis for precision breeding for BaMMV/BaYMV resistance. Theor Appl Genet. 2014;127:1625-34.

44. Chen JP, Adams MJ, Zhu FT, Wang ZQ, Chen J, Huang SZ, et al. Response of foreign barley cultivars to barley yellow mosaic virus at different sites in China. Plant Pathol. 1996;45:1117-25.

45. Chen J, Shi N, Cheng Y, Diao A, Chen J, Wilson TMA, et al. Molecular analysis of barley yellow mosaic virus isolates from China. Virus Res. 1999:64:13-21.

46. Rocherieux J, Glory P, Giboulot A, Boury S, Barbeyron G, Thomas G, et al. Isolate-specific and broad-spectrum QTLs are involved in the control of clubroot in Brassica oleracea. Theor Appl Genet. 2004;108:1555-63.

47. Li H, Shirako Y. Association of VPg and elF4E in the host tropism at the cellular level of barley yellow mosaic virus and wheat yellow mosaic virus in the genus Bymovirus. Virology. 2015;476:159-67.

48. Ohki T, Sano M, Asano K, Nakayama T, Maoka T. Effect of temperature on resistance to potato virus $Y$ in potato cultivars carrying the resistance gene Ry chc. Plant Pathol. 2018;67:1629-35.

49. Okada Y, Kashiwazaki S, Kanatani R, Arai S, Ito K. Effects of barley yellow mosaic disease resistant gene rym 1 on the infection by strains of barley yellow mosaic virus and barley mild mosaic virus. Theor Appl Genet. 2003;106:181-9.
50. Colmsee C, Beier S, Himmelbach A, Schmutzer T, Stein N, Scholz U, et al. BARLEX - the barley draft genome explorer. Mol Plant. 2015;8:964-6.

51. Henningsen E, Sallam AH, Matny O, Szinyei T, Figueroa M, Steffenson BJ. Rpg7: a new gene for stem rust resistance from Hordeum vulgare ssp. spontaneum. Phytopathology. 2021;111:548-58.

52. Ministry of Agriculture of the PRC. NYT 3060.4-2016.Code of practice for evaluation of barley varieties for resistance to disease-Part 4: yellow mosaic. Industry standard of Ministry of agriculture of China. 2016;4:1-5. (In Chinese).

53. Simko I, Piepho HP. The area under the disease progress stairs: calculation, advantage, and application. Phytopathology. 2012;102:381-9.

54. Fernando R, Grossman M. Marker assisted selection using best linear unbiased prediction. Genet Sel Evol. 1989;21:467.

55. Bates D, Mächler M, Bolker BM, Walker SC. Fitting linear mixed-effects models using Ime4. J Stat Softw. 2015;67:1-51.

56. Yeung P. SPSS survival manual: a step by step guide to data analysis using IBM SPSS. Aust N Z J Public Health. 2013;37:597-8.

57. Choudhury S, Hu H, Fan Y, Larkin P, Hayden M, Forrest K, et al. Identification of new QTL contributing to barley yellow dwarf virus-PAV (BYDV-PAV) resistance in wheat. Plant Dis. 2019;103:2798-803.

58. Chang HX, Wen Z, Tan R, Dong H, Wickland DP, Wang D, et al. Linkage mapping for foliar necrosis of soybean sudden death syndrome. Phytopathology. 2020;110:907-15.

59. Wu Y, Bhat P, Close TJ, Lonardi S. Efficient and accurate construction of genetic linkage maps from noisy and missing genotyping data. Algorithms bioinformatics WABI 2007. Lect Notes Comput Sci. 2007:4645:395-406.

60. Seifert E. OriginPro 9.1: scientific data analysis and graphing software software review. J Chem Inf Model. 2014;54:1552.

61. Van Ooijen JW. MapQTL ${ }^{\circledR}$ 6, Software for the mapping of quantitative trait loci in experimental populations of diploid species. Wageningen: Kyazma BV; 2009. https://www.kyazma.nl/index.php/MapQTL/.

62. Mccouch S, Cho Y, Yano M, Paul E, Blinstrub M, Morishima H. Report on QTL nomenclature. Rice Genet Newsl. 1997;14:1.

63. Voorrips RE. Mapchart: software for the graphical presentation of linkage maps and QTLs. J Hered. 2002;93:77-8.

64. Mascher M, Wicker T, Jenkins J, Plott C, Lux T, Koh CS, et al. Longread sequence assembly: a technical evaluation in barley. Plant Cell. 2021;33(6):1888-906.

65. Perovic D, Krämer I, Habekuss A, Perner K, Pickering R, Proeseler G, et al. Genetic analyses of BaMMV/BaYMV resistance in barley accession HOR4224 result in the identification of an allele of the translation initiation factor $4 \mathrm{e}(\mathrm{Hv}$-elF4E) exclusively effective against barley mild mosaic virus (BaMMV). Theor Appl Genet. 2014;127:1061-71.

66. Shi L, Jiang C, He Q, Habekuß A, Ordon F, Luan H, et al. Bulked segregant RNA-sequencing (BSR-seq) identified a novel rare allele of elF4E effective against multiple isolates of BaYMV/BaMMV. Theor Appl Genet. 2019;132:1777-88.

67. Mascher M, Gundlach H, Himmelbach A, Beier S, Twardziok SO, Wicker $T$, et al. A chromosome conformation capture ordered sequence of the barley genome. Nature. 2017;544:427-33.

68. Li H, Durbin R. Fast and accurate short read alignment with burrowswheeler transform. Bioinformatics. 2009:25:1754-60.

69. Li H, Handsaker B, Wysoker A, Fennell T, Ruan J, Homer N, et al. The sequence alignment/map format and SAMtools. Bioinformatics. 2009;25:2078-9.

70. Chen C, Chen H, Zhang Y, Thomas HR, Frank MH, He Y, et al. TBtools - an integrative toolkit developed for interactive analyses of big biological data. bioRxiv. 2020. https://doi.org/10.1101/289660.

\section{Publisher's Note}

Springer Nature remains neutral with regard to jurisdictional claims in published maps and institutional affiliations. 